\title{
CONSIDERAÇÕES A RESPEITO DO CONCEITO DE REAL EM LACAN
}

Wilson Camilo Chaves

\begin{abstract}
RESUMO. O presente trabalho visa elucidar a noção de real em Lacan no período que vai dos primeiros escritos ao Seminário, livro III, “As psicoses”, de 1955/1956. A discussão gira em torno das relações entre o imaginário e o real e entre o simbólico, o imaginário e o real. Lacan, primeiramente, atrela o imaginário ao real permeado pelo termo imago, cunhado por Freud. Logo em seguida, privilegia o simbólico e define a experiência psicanalítica como pertencente a esta ordem. No momento anterior,o real da experiência psicanalítica será da ordem do imaginário e nesse segundo instante será da ordem do simbólico. Tem-se aí a famosa tríade simbólico, imaginário e real. Mais à frente, em seu pensamento, o real vai ser definido como o que escapa ao simbólico. Tratar-se-á do impossível da relação sexual.
\end{abstract}

Palavras-chave: simbólico, imaginário e real, teoria lacaniana.

\section{CONSIDERATIONS REGARDING THE CONCEPT OF REAL IN LACAN}

\begin{abstract}
The present work seeks to elucidate the notion of Real in Lacan in the period that is going from the first writings to the Seminar, book III, " The psychoses ", of 1955/1956. The discussion rotates around the Imaginary and Real relationships; Symbolic, Imaginary and Real. Lacan, firstly, harnesses the Imaginary to the Real permeated by the term imago, happening of Freud. Therefore soon after, it privileges the Symbolic and it defines the experience analytic as being of this order. In the previous moment, the Real of the experience analytic will be of the order of the Imaginary. In that second instant, the Real of the analytic experience will be of the order of the Symbolic. Then we have, the famous triad, Symbolic, Imaginary and Real. More ahead, in your thought, the Real will be defined as what it escapes to the Symbolic. It will be treated of the impossible of the sexual relationship.
\end{abstract}

Key words: Symbolic, imaginary and real; Lacan's theory.

\section{LAS CONSIDERACIONES CON RESPECTO AL CONCEPTO DE REAL EN LACAN}

RESUMEN. El presente trabajo busca elucidar la noción de Real en Lacan en el período que se extiende de las primeras escrituras al Seminario, libro III," Las psicosis", de 1955/1956. La discusión rueda alrededor de las relaciones Imaginario y Real; Simbólico, Imaginario y Real. Lacan, primeramente, ata el Imaginario al Real penetrado por el término imago, proveniente de Freud. Por consiguiente, poco después, privilegia el Simbólico y define la experiencia psicoanalítica como siendo de este orden. En el momento anterior, el Real de la experiencia psicoanalítica será del orden del Imaginario. En un según momento, el Real de la experiencia analítica será del orden del Simbólico. Hay allí, la triada famosa, Simbólico, Imaginario y Real. Adelante, en su pensamiento, el Real se definirá como lo que escapa del Simbólico. Se tratará del imposible de la relación sexual.

Palabras-clave: Simbólico, imaginario y real; teoría lacaniana.

A noção de Real recebeu algumas conotações ao longo da teoria lacaniana, o que não significa que Lacan não tenha se dedicado a ela tal como fizera com os outros dois registros - Imaginário e Simbólico. Diferente é a posição de Roustang (1988), que afirma: "Não existe nenhum texto em que o real seja por si mesmo objeto de um desenvolvimento. A palavra aparece aqui e ali, como se seu sentido dependesse da evidência" (p. 50). Queremos, neste artigo, resgatar a noção de Real desde sua relação com o Imaginário, bem como lançar luzes a respeito de sua relação com o Simbólico, focalizando-o, assim, num momento bastante específico da obra de Lacan.

* Psicanalista. Doutor em Filosofia. Professor do Departamento de Psicologia da Universidade Federal de São João del ReiUFSJ/MG. 


\section{IMAGINÁRIO E REAL}

No artigo Para-além do 'Princípio de realidade' de 1936, Lacan se esforça, tal como acontecera desde a tese de 1932, em apreender objetivamente o fenômeno psíquico por meio da experiência psicanalítica, criticando o associacionismo de uma maneira geral e, de maneira mais específica, a psicologia associacionista, que visa a "uma garantia da verdade" (Lacan, 1998, p. 78), deixando, com isso, de ser "simplesmente positiva". Para Lacan, a psicologia associacionista deve ser substituída pela psicologia da forma, na esteira da fidelidade à "revolução freudiana" (p. 78). Na Tese de 1932, "Da psicose paranóica em suas relações com a personalidade", Lacan (1975) havia proposto fazer uma "análise concreta do psiquismo" que pudesse conduzir a um determinismo específico da subjetividade. Esforçara-se em analisar objetivamente o subjetivo, o sujeito concreto, lançando "sobre o caso estudado um olhar tão nu, tão objetivo quanto possível" (Lacan, 1975, p. 247). Dessa maneira, em ambos os textos - a tese de 1932 e o artigo de 1936 - Lacan objetiva reivindicar uma positividade para a psicologia freudiana. Trata-se de certa influência do pensamento sociológico de Augusto Comte. No texto de 1936 Lacan vai se preocupar também com os dados concretos, porém, tratar-ser-á dos dados concretos da imagem. O associacionismo, a seu ver, empobrece consideravelmente a riqueza dos dados. É o conceito de imagem que Lacan privilegiará para contrapor à visão associacionista.

No texto de 1936, Lacan enfatiza a imagem, valorizando-a como um fenômeno privilegiado da investigação psicanalítica, pois é "o mais importante da psicologia pela riqueza de seus dados concretos, o é também pela complexidade de sua função, complexidade esta que não se pode tentar abarcar num único termo, a não ser o de função de informação" (Lacan, 1998 p. 81). O associacionismo, porém, reduz o fenômeno da imagem à sua função de ilusão, isto é, exclui a imagem, considerando-a como uma "sensação enfraquecida, na medida em que, aberta menos seguramente à realidade, ela é tomada por eco e sombra da sensação, portanto, identificada, com seu traço, com o engrana" (Lacan, 1998, p. 81). Assim, para Lacan (1998), o associacionismo jamais vai ascender a uma psicologia autêntica, "que sabe que uma certa intencionalidade é fenomenologicamente inerente a seu objeto" (p. 82). Pertencem à realidade verdadeira, segundo o raciocínio do associacionismo, somente aqueles fenômenos que se inserem em algum nível das operações do conhecimento racional.
Sentimentos, crenças, delírios, assentimentos, intuições, sonhos, etc. são explicados, segundo Lacan (1998), pelo associacionismo com "algum determinismo estranho à sua 'aparência' e chamado de 'orgânico', por reduzi-los, quer ao suporte de um objeto físico, quer a relação de um fim biológico"(p. 82). Lacan, seguindo Freud, vai dar outra conotação a esses fenômenos, cujo status é relegado à categoria de ilusão. Seu objetivo é inscrever a sua psicologia no terreno da ciência, não nos moldes do associacionismo, mas no da psicanálise freudiana, isto é, na experiência analítica que se fundamenta no real. De que Real se trata nesse início do ensino de Lacan? A afirmativa lacaniana citada abaixo começa a elucidar essa importante noção:

\begin{abstract}
A ciência estava bem posicionada para servir de objeto último à paixão pela verdade, despertando no vulgo a prosternação diante do novo ídolo que chamou de cientificismo e, no 'letrado', esse eterno pedantismo que, por ignorar o quanto sua verdade é relativa às muralhas de sua torre, mutila o que do real lhe é dado a apreender (Lacan, 1998, p. 83)
\end{abstract}

Trata-se, assim, de desbravar outro caminho, uma terceira via, talvez, que não incorresse em nenhum reducionismo, nem no cientificismo nem no "letrado". É por essa razão que, para Lacan, a psicologia não constitui uma ciência, na medida em que se volta para a verdade, impossibilitando apreender o Real. O fim da verdade é outro que não o da ciência. A ciência pode até "honrar-se de suas alianças com a verdade, pode propor-se como objetivo seu fenômeno e seu valor, mas não pode de maneira alguma identificá-la como seu fim próprio" (Lacan, 1998, p. 83). Desse modo, não escapa à critica de Lacan nem mesmo o próprio médico, que despreza a realidade psíquica e cuja "formação academicista" o impede de uma observação totalizante do sujeito, caindo em "concepções como a de piatismo" (Lacan, 1998, p. 84). Não obstante, Freud, segundo Lacan, embora médico, opôs-se radicalmente a essa proposta, criando outra positividade e operando uma verdadeira revolução metodológica, na medida em que, ao escutar o sujeito, dá importância ao seu testemunho, que é o primeiro sinal dessa atitude de submissão do Real em Freud. O Real já tem importância nesse início do pensamento de Lacan, ainda que, como se verificará, atrelado ao Imaginário. É a tríade que se começa a formar. Nesse texto de 1936, "Para além do princípio de realidade" e em outros desse período só se atinge o Real pelo Imaginário. Mais à frente, em meados dos anos de 1950, só se vai ao real pelo simbólico. A partir 
dos anos de 1960 e, mais especificamente, 1964, o Real será definido como o que escapa ao Simbólico, o real como trauma. Entretanto, já no Seminário, livro 7, dedicado à ética, de 1959/1960, a ética da psicanálise será centrada não no ideal, mas no real da experiência psicanalítica. Há uma valoração do real, embora em cada momento da obra de Lacan este conceito vá se evidenciando de acordo com os dois outros registros, o Imaginário e o Simbólico, até se entrelaçarem de uma vez por todas, no final de seu pensamento, no nóborromeano.

Ao longo do texto de 1936, Lacan elogia Freud, ainda que de forma moderada (Marcos, 2003). Ao criticar a medicina e a psicologia associacionista, que identifica o imaginário com o ilusório, o que Lacan denuncia é quanto tal identificação despreza "o que tem significação real, o sintoma" (Lacan, 1998, p. 85), concebendo-o como um epifenômeno, ou seja: se é psicológico, sê-lo-á somente na aparência. O sintoma precisa ser distinguido do "registro da vida comum da vida psíquica por algum traço discordante onde se mostre bem seu caráter 'grave"'(Lacan, 1998, p. 85). A experiência psicanalítica, para Lacan, tem regras claras, que, em Freud, encontram-se condensadas em uma única, a lei da associação livre. O termo-chave é a linguagem, na medida em que mantém significativa relação com o pensamento do sujeito: a linguagem "por ser abordada por sua função de expressão social, revela ao mesmo tempo sua unidade significativa na intenção e sua ambigüidade constitutiva como expressão subjetiva, depondo contra o pensamento, sendo mentiroso com ele" (Lacan, 1998 a, p. 86-87). Essa relação entre linguagem e pensamento desdobrase na relação entre o analista e o analisando, tocando, dessa forma, na transferência. Assim, o que importa não é o que se diz, mas o que se lhe diz, pois, "a linguagem antes de significar alguma coisa, significa para alguém" (Lacan, 1998, p. 86). Marcos (2003) considera que Lacan, ao fazer tal afirmativa, não quer dizer que "a linguagem signifique apenas o sujeito da enunciação, mas que aquilo que ela significa (coisa ou ser) ela significa primeiramente para alguém"(p. 333). Se não há alguém a quem se dirigir, não há por que falar. O interlocutor, o psicanalista, por excelência, tem um papel fundamental:

Pelo simples fato de estar presente e escutar, este homem que fala dirige-se a ele, e, já que ele impõe a seu discurso não querer dizer nada, resta o que esse homem quer lhe dizer. $\mathrm{O}$ que ele diz, com efeito, pode 'não ter nenhum sentido', mas o que ele lhe diz contém um sentido. É no movimento que o ouvinte o sente; é suspendendo esse movimento que ele compreende o sentido do discurso (p. 86).

O ouvinte entra nessa experiência "na situação de interlocutor" (Lacan, 1998, p. 87). O ouvinte é o analista. $\mathrm{O}$ sujeito solicita o analista, inicialmente, de maneira implícita, para, logo em seguida, solicitá-lo explicitamente. Lacan (1998), entretanto, adverte que o psicanalista permanece silencioso e resiste pacientemente a isso:

Não haverá um limite em que essa atitude deva fazer cessar o monólogo? Se o sujeito prossegue nele, é em virtude da lei da experiência; mas, acaso continua ele a dirigir ao ouvinte realmente presente, ou antes, agora, a algum outro, imaginário porém mais real; ao fantasma da lembrança, à testemunha da solidão, à estátua do dever, ao mensageiro do destino? (p. 87).

Explicita-se, dessa maneira, a relação entre o Imaginário e o Real, isto é, o Imaginário ganha uma dimensão de Real. De acordo com Marcos (2003), “o índice de realidade do outro não é, pois, sua presença. Sua presença enquanto pessoa física no aqui e agora, não pode garantir sua realidade se o outro 'mais real' mostrase bem presente apesar de sua ausência” (p. 338). Assim, é da reconstituição da imagem pelo sujeito que se trata, na medida em que a experiência psicanalítica prossegue: "a conduta deixa de imitar sua sugestão, as lembranças retomam sua densidade real, e o analista vê o fim de seu poder, doravante inutilizado pelo fim dos sintomas e pelo arremate da personalidade" (Lacan, 1998, p. 88). Lacan aponta para a situação de que o analisando deve se deparar com o Real produzido pela reconstituição da imagem, que agora já não é tão ilusória, pois o trabalho da psicanálise, do analista, especificamente, consiste justamente em "resolver uma ilusão"; ou seja, para Lacan (1998), a ação terapêutica

deve ser essencialmente definida como um duplo movimento pelo qual a imagem, a princípio difusa e fragmentada, é regressivamente assimilada ao real, para ser progressivamente desassimilada do real, isto é, restaurada em sua realidade própria. Ação que testemunha a eficiência dessa realidade (p. 89).

Roustang (1988, p. 50) comenta a respeito dessa importante afirmativa de Lacan:

A imagem, como gestalt formadora que importa reconstituir, não é o real, mas é da ordem do real, de onde é preciso retirá-la. 
Esse real deve ser dito eficiente, já que a imagem que dele participa determina e constitui o sujeito. Ele é a razão da permanência através da mudança incessante das aparências. Pelo real, graças a ele, o objeto da psicanálise, pode ser creditado dos traços da objetividade.

Não se pode perder de vista o projeto que Lacan está elaborando nesse momento de sua obra, que é o de dar à psicologia um status de ciência. Segundo Roustang (1988), é a Meyerson, relativista, que Lacan recorre a fim de fundamentar suas premissas. Lacan adota, também, a mesma perspectiva de Henri Wallon em relação à imagem especular e "opõe o real à 'realidade própria' da imagem" (Marcos, 2003, p. 349). Trata-se de "retirar a imagem da ordem do mimetismo a fim de restituí-la em sua dimensão de lembrança" (Marcos, 2003, p. 349). Para Marcos (2003), este programa ambicioso de Lacan, nesse período de sua obra, consiste em almejar "entre outras coisas, fazer desaparecer o termo 'inconsciente' em prol da imago". E o Real? Roustang (1988) afirma a respeito do conceito de real que Lacan

\begin{abstract}
talvez nunca tenha renunciado aos traços principais que, nessa época, formavam a compreensão desse conceito: o real é um invariante, que consiste e resiste, é independente do eu e da consciência, é o ser de todos os fenômenos, é, enfim, racional, e por essa razão é matematizável e logizável (p. 51).
\end{abstract}

De acordo ainda com Roustang (1988), o Real, depois de 1936 vai desaparecer de cena por algum tempo e só voltará a ocupar um lugar de destaque no final de 1955, no seminário dedicado às psicoses. Contrariamente a esse autor, podemos afirmar que, nesse intervalo entre 1936 e 1955, o conceito de Real aparecerá em importantes textos, como o texto de 1951, "Intervenção sobre a Transferência" e, nos de 1953, "Função e campo da linguagem em psicanálise", "O mito individual do neurótico", de 1952 e "O Simbólico, o Imaginário e o Real", de 1953, bem como no Seminário II, "O Eu na teoria de Freud e na técnica da psicanálise", de 1954-1955. Entre os textos acima citados destacaremos os dois últimos, a fim de elucidar a relação entre real, imaginário e simbólico nesse período do ensino de Lacan.

\section{SIMBÓLICO, IMAGINÁRIO E REAL}

No texto "O Simbólico, o Imaginário e o Real', Lacan (2005) introduz esses três registros como os essenciais da realidade humana. Vanier (2005) sintetiza, de maneira simples e coesa, o entendimento de Lacan a respeito desses três registros, nesse início de seu pensamento:

\begin{abstract}
O Simbólico remete simultaneamente à linguagem e à função compreendida por Lévi-Strauss como aquela que organiza a troca no interior dos grupos sociais; o Imaginário designa a relação com a imagem do semelhante e com o 'corpo próprio'; o Real, que deve ser distinguido da realidade, é um efeito do Simbólico: o que o Simbólico expulsa, instaurando-se. Essas definições antecipam o que Lacan propõe em 1953 (p. 18-19).
\end{abstract}

Sob a égide de um retorno a Freud, Lacan propõe a tríade a fim de elucidar as instâncias introduzidas por Freud, denunciando os desvios cometidos alémmar pelos defensores de uma psicologia do ego, que estavam transformando a psicanálise numa teoria adaptativa. Lacan coloca em questão "a representação corrente de uma psicanálise comparável às disciplinas científicas" (Vanier, 2005, p. 20). É à Antropologia estruturalista que, nesse momento de sua obra, Lacan recorre para solidificar seu programa de dar à psicanálise um estatuto de ciência. A justificativa que encontra Lacan para que se volte à fonte da Psicanálise se fundamenta na proposição de que a experiência freudiana aborda a realidade humana na sua totalidade. Para Lacan, não haveria nenhuma outra experiência que conseguiria esse feito. Assim, voltar às fontes da Psicanálise é denunciar a degradação que esta disciplina vinha sofrendo. Isto é, para Lacan, a teoria não deve ser dissociada de sua técnica. A fim de entender a realidade humana é preciso enfatizar os três registros que a compõem: o Simbólico, o Imaginário e o Real. Segundo Vanier (2005), os registros Imaginário e Real são remanejados e fundados a partir do Simbólico. O Simbólico é, então, trazido ao primeiro plano, pois, no texto de 1953 sobre a tríade, a experiência analítica é a que se dá na fala (ou em palavras):

É de fato assim que devemos entender o simbólico de que se trata na troca analítica. Quer se trate de sintomas reais ou atos falhos, ou o que quer que seja que se inscreva no que encontramos e reencontramos incessantemente, e que Freud manifestou como sendo sua realidade essencial, trata-se ainda e sempre de símbolos, e de símbolos organizados na linguagem, portanto, funcionando a partir da articulação do significante e do significado, 
que é o equivalente da estrutura da linguagem (Lacan, 2005, p.22).

Mas há também o Imaginário e o Real que, de certa maneira, encontram-se imbricados com o Simbólico. A fantasia, que é da ordem do Imaginário, "tem valor estritamente simbólico", pois "ela é feita para se exprimir, para ser dita, para simbolizar alguma coisa que tem um sentido diferente, de acordo com o momento do diálogo" (Lacan, 2005, p. 22). Assim, o que interessa a Lacan é desvendar o que se dá na experiência psicanalítica. É dela que o psicanalista sempre parte para indagar a respeito de quem é esse neurótico com quem se lida nessa experiência psicanalítica, bem como para dar conta da consistência da passagem do consciente para o inconsciente, e ainda, indagar a respeito das "forças" que "dão certa existência a esse equilíbrio, e que chamamos de princípio de prazer" (Lacan, 2005, p. 16). A experiência psicanalítica não poderá se reduzir ao Imaginário, na medida em que este não se confunde, de maneira alguma, com o analisável. Não obstante, o que é da ordem do Imaginário no homem difere do que é da ordem do imaginário no animal. Para o homem, o Imaginário se apresenta de outra forma. $\mathrm{O}$ Imaginário de que se trata numa análise, para Lacan, só o é na medida em que represente outra coisa que não a ele mesmo, pois, nesse momento de sua obra, tudo o que se pode analisar é da ordem do Simbólico. Trata-se, então, não de indagar a respeito da origem da linguagem - pois, uma vez emergida, já não é possível saber como começou, nem mesmo como era antes de sua existência - mas de dizer a respeito de sua função. A constituição do sujeito se dará no registro do Simbólico (Chaves, 2005). A significação do símbolo está associada ao automatismo de repetição, concebido e exemplificado primeiramente por Freud: refere-se ao brinquedo com o carretel que a criança faz aparecer e desaparecer conforme a chegada e a saída da mãe:

Essa repetição primitiva, essa escansão temporal, faz com que a identidade do objeto seja mantida na presença e na ausência. Temos com isso o alcance exato, a significação do símbolo na medida em que ele se refere ao objeto, isto é, ao que denominamos conceito (Lacan, 2005, p. 35).

Assim, para Lacan, o humano só o é se tem acesso ao símbolo. O símbolo está intimamente ligado ao tempo, à duração, e por ter durado, ou seja, existido no tempo, é significativo, é simbólico: "Quanto mais humano, mais preservado do lado movediço e descompensante do processo natural. $\mathrm{O}$ homem faz subsistir em uma certa permanência tudo o que durou como humano, e, antes de tudo, ele próprio" (Lacan, 2005, 36). Lacan (2005) critica demasiadamente todos aqueles que após Freud desconsideraram "a função simbólica da linguagem", enfatizando o Imaginário pela via da resistência, em desconsideração à importante noção de pulsão de morte. Assim, enfatizar o aspecto irredutível e imprescindível do pensamento de Freud, o instinto de morte, é valorizar o que fez com que ele o estabelecesse, a saber, o automatismo de repetição.

Na experiência analítica, para além do Imaginário, há o Simbólico e o Real. O Simbólico garante o que transcende para que o sujeito não se consuma em si mesmo. Institui-se assim o "outro como outro", garantindo a não-alienação para sempre em sua imagem, reflexo de si mesmo. O Real, na experiência psicanalítica, é "ou a totalidade ou o instante esvanecido" (Lacan, 2005, p. 45). Nota-se quanto o Real, nesse instante do pensamento de Lacan, está atrelado ao Simbólico:

Que Freud tenha introduzido aí o amor é algo que deve nos mostrar a que ponto ele deva às relações simbólicas seu alcance no plano humano. Com efeito, se devemos dar sentido a esse algo limítrofe o qual mal podemos falar que é o amor, é este - a conjugação total da realidade e do símbolo, que fazem uma única e mesma coisa (Lacan, 2005, p. 50).

Lacan dá ao amor um estatuto de real, do impossível de se dizer, ou melhor, do que mal se pode falar. Mais uma vez, Real e Simbólico se entrelaçam, pois "a encarnação do amor é o dom do filho, que, para um humano, tem esse valor de algo mais real" (Lacan, 2005, p. 51). O dom, o símbolo, para Lacan, ultrapassa a fala.

No Seminário, livro III, "As psicoses", Lacan (1992a) dirá que o Real é o que retorna sempre ao mesmo lugar. Mas será no Seminário, livro II, “O Eu na teoria de Freud e na técnica da psicanálise", proferido nos anos de 1954/1955, que Lacan (1992b) afirmará que o Real é sem fissura e que só é possível apreendê-lo por intermédio do Simbólico. Lacan critica, então, toda ciência que supostamente aborda o Real sem levar em conta o Simbólico. Tal ciência, sem o saber, acaba se dirigindo a um simbolismo. Para a psicanálise, especificamente, o simbolismo é essencial. De acordo com Lacan (1992b), este simbolismo tem um nome: repetição, que deve ser concebida "como ligada a um processo circular do intercâmbio da fala" (p. 129). Assim, sob a ótica de Lacan, na psicanálise descarta-se - pelo menos nesses 
primeiros anos - qualquer possibilidade de elaboração de seu pensamento, de uma relação do sujeito com o objeto que não passe pelo simbólico, pois a repetição, enquanto pertencente ao campo do Simbólico, tem a função de reestruturar o mundo. O ponto da relação do sujeito com o Simbólico vai ser buscado por Lacan lá onde Freud, nos sonhos, denominou de umbigo do sonho. Trata-se de um ponto inapreensível. Nesse Seminário II, Lacan (1992b) denuncia certo realismo das psicologias ao se voltar para os limites, as capacidades individuais. Segundo Zizek (1991), nos anos 1970 Lacan introduz a diferença entre Real e realidade e enfatiza o Real como pertencente à ordem do impossível. Entretanto, ressalta Zizek (1991, p. 71) que "esse real impossível está em ação antecipadamente, articulado em termos diferentes, já em numerosas passagens do Lacan dos anos cinqüenta".

No Seminário, livro III, dedicado às psicoses, Lacan (1992a) analisa com mais profundidade o conceito de significante, uma vez que é justamente na psicose que melhor se evidencia a supremacia do significante sobre o significado, pois é ali onde o significante falta, ou seja, na psicose, que ele demonstra mais sua força. $\mathrm{O}$ sujeito psicótico, dessa maneira, coloca em questão o conjunto dos significantes, o significante enquanto tal. O Real será, nesse Seminário, definido como o que retorna sempre ao mesmo lugar. Essa definição terá um grande peso, pois em alguns seminários dos anos seguintes Lacan a ela recorrerá várias vezes para definir o que é da ordem do Real.

\section{CONCLUSÃO}

Vimos que Lacan inicialmente se debruça sobre o fenômeno psíquico a fim de apreendê-lo através de uma nova positividade, denunciando a psicologia associacionista, que reduz a imagem à condição de ilusão. O pivô da empresa de Lacan girará em torno do termo Imago, retomado da obra freudiana, mas já trabalhado por Wallon, na condição de imagem especular. Lacan cunha o Estádio do Espelho e eleva a imagem ao patamar da ordem do Real. Temos, aqui, dois elementos da tríade, o Imaginário e o Real. O Imaginário humano distingue-se do imaginário animal, pois está inserido na ordem da linguagem, portanto é artigo de representação. Há, assim, o Simbólico, responsável pela constituição, propriamente dita, do sujeito. Nesse momento de sua obra, sob a influência do Estruturalismo de Lèvi-Strauss e da Lingüística de
F. Saussure e Jacobson, a experiência psicanalítica já não será mais da ordem do Imaginário, constituirá uma práxis simbólica. É o Simbólico que se eleva à categoria de Real ou melhor, só se vai ao Real pelo Simbólico. Mais à frente, em sua obra, Lacan conceberá o Real como sendo da ordem do Impossível, o que escapa ao Simbólico. O Real será atrelado ao aforismo "não há relação sexual". Ter-se-á o impossível da relação sexual, isto é, a impossibilidade de sua inscrição no Simbólico.

\section{REFERÊNCIAS}

Chaves, W. C. (2005). A determinação do sujeito em Lacan: da reintrodução na psiquiatria à subversão do sujeito. São Carlos: Edufscar.

Lacan, J. (2005). O simbólico, o imaginário e o real. Em Nomes-doPai (T. André, Trad., pp.11-53). Rio de Janeiro: Jorge Zahar (Original publicado em 1953).

Lacan, J. (1998). Para além do "Princípio de realidade". Em Escritos (R. Vera, Trad., pp.77-95). Rio de Janeiro: Jorge Zahar (Original publicado em 1936).

Lacan, J. (1992a). O Seminário, livro III. Em As psicoses (M. Aluísio, Trad.). Rio de Janeiro: Jorge Zahar (Original publicado em 1955/1956).

Lacan, J. (1992b). O Eu na teoria de Freud e na técnica da psicanálise (L. P. Marie Christine, Trad.). Rio de Janeiro: Jorge Zahar (Original publicado em 1954/1955).

Lacan, J.(1964/1990). O Seminário, livro XI, Os quatro conceitos fundamentais da psicanálise. (M. D. magno, Trad.). Rio de Janeiro: Jorge Zahar (Original publicado em1973).

Lacan, J. (1959/1960/1988). O Seminário, livro VII, A ética da psicanálise (Q. Antonio, Trad.). Rio de Janeiro: Jorge Zahar (Original publicado em 1986).

Lacan, J. (1975). De la psychose paranö̈aque dans ses rapports avec la personnalité. Paris: Seuil (Original publicado em 1932).

Marcos, J. (2003). Subversão da imagem: contribuição a uma leitura de "Para além do princípio de realidade". Em V. Safatle (Org.), Um limite tenso: Lacan entre a filosofia e a psicanálise (S. Vladimir, Trad., pp. 331-366). São Paulo: Unesp.

Roustang, François. (1988). Lacan: do equívoco ao impasse (C. Roberto, Trad.). Rio de Janeiro: Campus.

Vanier, A. (2005). Lacan. (B. Nícia Adan, Trad.). São Paulo: Estação Liberdade (Original publicado em 1998).

Zizek, S. (1991). O mais sublime dos histéricos (R. Vera, Trad.). Rio de Janeiro: Jorge Zahar.

Recebido em 27/09/2007 Aceito em 08/07/2008

Endereço para correspondência : Wilson Camilo Chaves, Rua Bias Fortes, 255 Bairro: Centro Cep. 37130.000 Alfenas-MG, Brasil.E-mail: camilo@ufsj.edu.br 